\title{
HASTE MRI in the assessment of children with hydrocephalus
}

\author{
Samuel R Browd", Brent R O'Neill, Sumit Pruthi, Harmanjeet Bains, Ryan Robison, Keiko Weir, Jeff Ojemann, \\ Anthony Avellino, Richard Ellenbogen
}

From 54th Annual Meeting of the Society for Research into Hydrocephalus and Spina Bifida

Vancouver, Canada. 7-10 July 2010

\section{Background}

Recent reports and our clinical experience have shown the usefulness of rapid-acquisition MRI in evaluating children with hydrocephalus. An axial HASTE (i.e. Half-Fourier Acquisition Single-shot Turbo Spin Echo Magnetic Resonance Imaging) MRI study acquires clinically useful images in seconds without exposing children to the risks of ionizing radiation or sedation. The current report reviews the Seattle Children's Hospital experience with rapid acquisition MRI in shunted children with attention to ventricular size, overall image quality, motion artifact, and catheter visualization.

\section{Materials and methods}

All HASTE MRIs obtained at Seattle Children's Hospital over two-years were reviewed by two evaluators on scales of overall image quality, catheter visualization, motion artifact, and ventricular size. Relationships among these factors were sought.

\section{Results}

Overall image quality was rated very good or excellent in $94 \%$ of the studies reviewed, while only one study was graded as poor. Significant motion artifact was noted in $7 \%$ while $77 \%$ had little or no motion artifact. Catheter visualization was rated as good or excellent in $57 \%$ of studies reviewed, poor in $36 \%$, and misleading in $7 \%$. Small ventricular size showed a significant correlation with poor catheter visualization (Pearson correlation coefficient $=$ .575; $\mathrm{p}<.00001)$. Ventricular enlargement concerning for shunt malfunction on HASTE imaging correlated with operative findings of shunt malfunction in $100 \%$ of cases taken to the OR based on HASTE imaging.

\footnotetext{
* Correspondence: samuel.browd@seattlechildrens.org
Department of Neurological Surgery Seattle Children's Hospital PO Box 5371,

* Correspondence: samuel.browd@seattlechildrens.org
Department of Neurological Surgery Seattle Children's Hospital PO Box 5371, Seattle, WA 98105-0371, USA
}

(c) 2010 Browd et al; licensee BioMed Central Ltd. This is an open access article distributed under the terms of the Creative Commons Attribution License (http://creativecommons.org/licenses/by/2.0), which permits unrestricted use, distribution, and reproduction in any medium, provided the original work is properly cited.

\section{Conclusions}

Our study adds further support to the emerging evidence that HASTE MRI is an adequate substitute for CT scanning allowing for reduced utilization of $\mathrm{CT}$ imaging and resultant exposure to ionizing radiation. Visualization of catheter position remains suboptimal with HASTE MRI, particularly when ventricles are small; however, shunt malfunction can be adequately determined based on ventricular size alone in the majority of cases.

Published: 15 December 2010

Cite this article as: Browd et al: HASTE MRI in the assessment of children with hydrocephalus. Cerebrospinal Fluid Research 2010 7(Suppl 1): S36. and take full advantage of:

- Convenient online submission

- Thorough peer review

- No space constraints or color figure charges

- Immediate publication on acceptance

- Inclusion in PubMed, CAS, Scopus and Google Scholar

- Research which is freely available for redistribution 